\title{
Iatrogenic endometrial patterns
}

\author{
D. CHARLES \\ From the University Department of Pathology, Western Infirmary, Glasgow
}

SYNOPSIS The histological patterns exhibited in the endometrium due to the newer progestational agents cannot be correlated with the patient's menstrual cycle or the physiological endometrium which follows ovulation. The oral progestational agents which have been produced during the past few years have had wide clinical application. Although the 19-nor-steroids and the derivatives of $17 \alpha$ hydroxyprogesterone differ in chemical structure, they produce similar histological appearances in the endometrium. Prolonged use of these compounds produces atrophy of the endometrial glands and a cellular stroma which might be mistaken for endometrial sarcoma. In view of the fact that such compounds are widely used in clinical practice and as contraceptive agents, it is essential that the pathologist should be aware of the bizarre endometrial patterns which they may produce; the more important of these changes are illustrated and discussed.

Evaluation of morphological and functional changes based on histological examination of the endometrium establishes a rational diagnostic basis for clinical therapy. In the normal menstrual cycle the endometrium undergoes a post-menstrual reparative process under the influence of oestrogen. It is logical to consider oestrogen as the growth factor to the endometrium, since mitoses are present in both gland and stromal cells during the proliferative phase of the cycle. The prolonged administration of oestrogens to women for climacteric symptoms or breast carcinoma will result in an endometrial pattern comparable with that of endometrial hyperplasia (Figs. 1 and 2).

In the normal menstrual cycle, following ovulation the effects of progesterone result in the well-known changes associated with the secretory phase of the cycle. These changes comprise the enlargement and differentiation of the stromal cells to form 'decidualike' cells, the presence of stromal oedema and tortuous glands, with evidence of glycogen secretion either in the cells or the lumina of the glands.

The evaluation of endometrial patterns is difficult since considerable variations are present in normal curettings because the endometrium is obtained from various sites in the uterus. The influence of location on histological interpretation can be illustrated by the diminished hormonal responsiveness of the endometrium in the lower part of the uterine cavity compared with that in the fundus (Figs. 3 and 4).

Received for publication 10 January 1964.

3
The endometrium usually responds to the ovarian hormones in a more or less well-defined pattern. The deviations from the normal in functional disorders of menstruation have been extensively studied but the unusual patterns produced by the oral progestational compounds are not yet well known to the clinical pathologist and have considerably complicated his task of formulating a diagnosis from the histological examination of endometrial tissue. The interpretation of endometrial histology is highly subjective and it is mandatory that the pathologist be in possession of all relevant clinical information.

In the past decade the biochemist has provided the clinician with many steroid compounds which exhibit progestational activity. Any compound which is proposed as a substitute for progesterone should influence the endometrium, and in this paper the various types of endometrial pattern produced by the newer and more potent progestational agents will be described. From the point of view of the pathologist it is essential that he is aware of these synthetic steroids since these agents produce an endometrial pattern that is rarely seen in patients who have not received such hormonal therapy.

The newer progestational agents which are widely used in clinical practice fall into two groups of different chemical structure. The derivatives of the 19-nor-steroids, of which norethisterone and norethynodrel are examples, were the first compounds to be used. Recently derivatives of 17ahydroxyprogesterone, such as 17ahydroxyprogesterone caproate and $\Delta^{6}$ chloracetoxyprogesterone, have been introduced. All these compounds, except for 


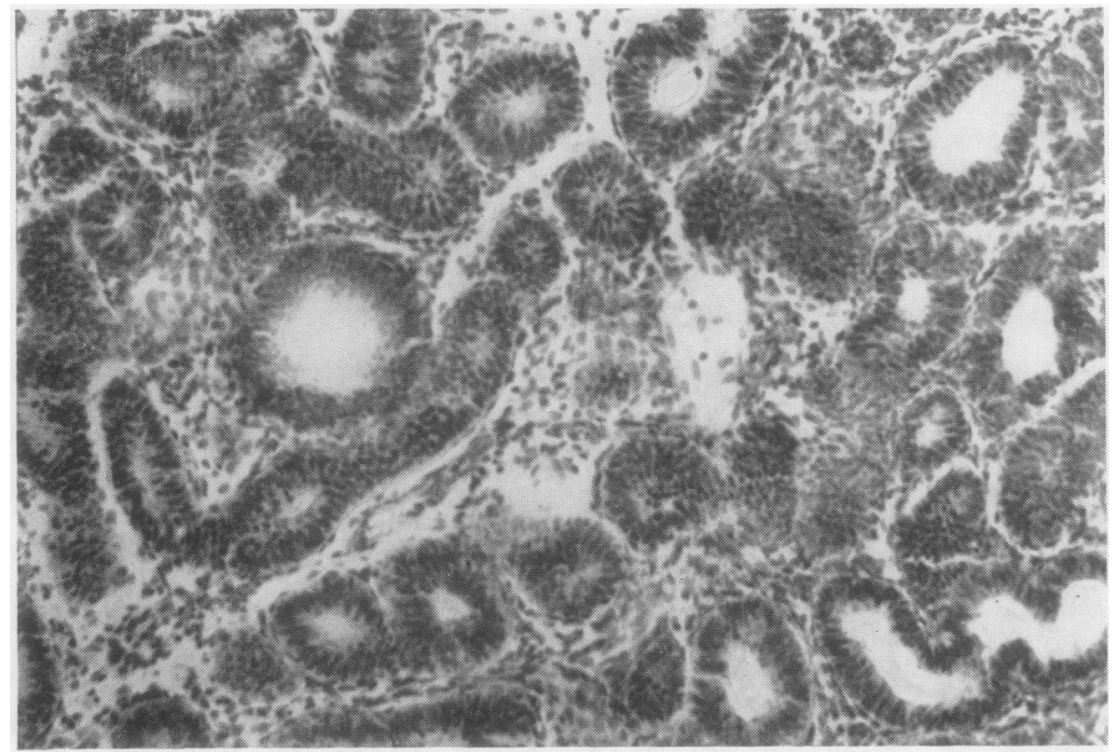

FIG. 1. Endometrium after three months' diethylstilboestrol therapy; note frequency and proximity of glandular elements. Haemalum and eosin $\times 174$.

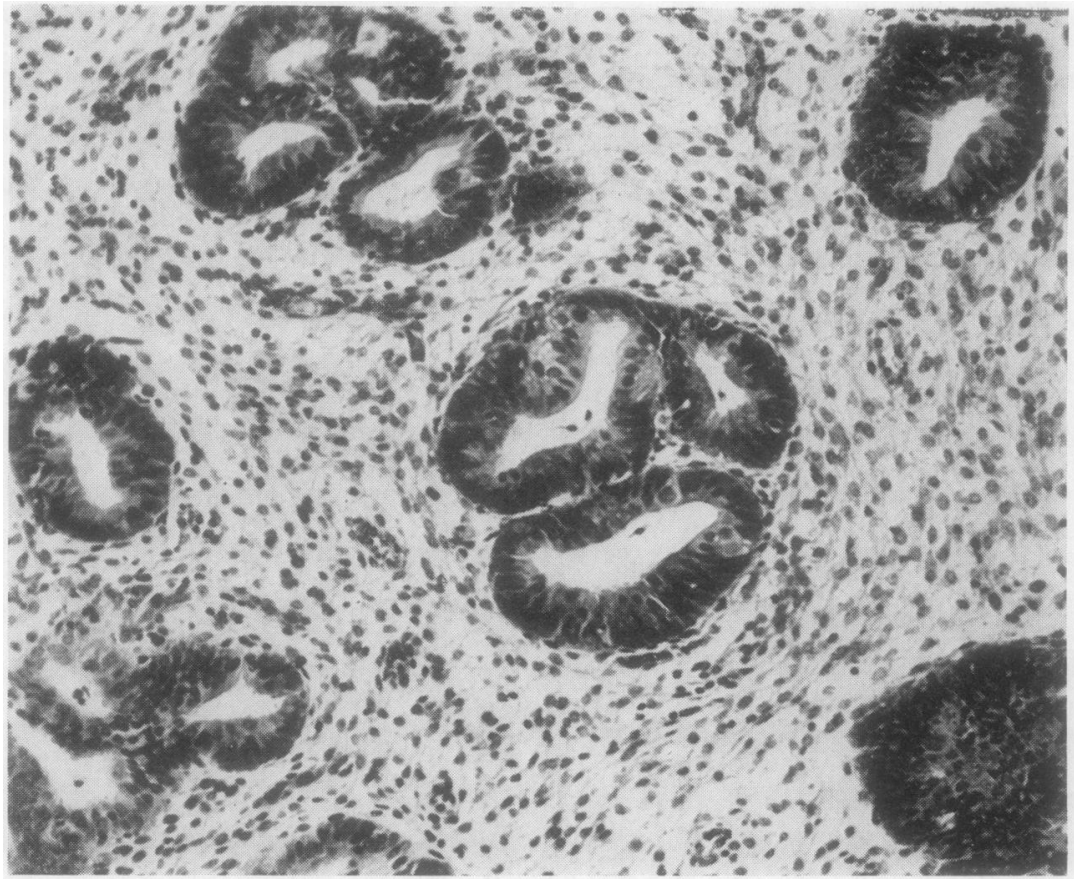

FIG. 2. Endometrium after three months' diethylstilboestrol therapy; in contrast to Fig. 1 there is still abundant stroma but the glands show a pattern similar to adenomatous endometrial hyperplasia. Haemalum and eosin $\times 174$. 


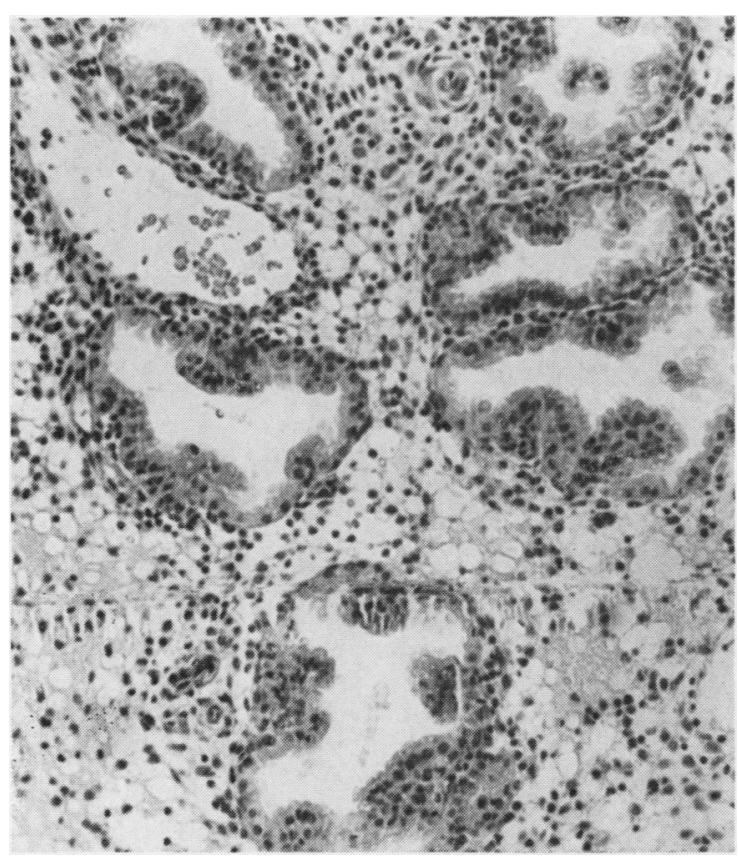

FIG. 3. Endometrium from upper segment obtained on the twenty-fifth day of the menstrual cycle showing obvious secretory changes. Haemalum and eosin $\times 119$.

17ahydroxyprogesterone caproate, are active when administered orally.

The inhibition of ovulation by these agents in the management of dysmenorrhoea, endometriosis, and as contraceptive agents will result in atypical endometrial patterns being more frequently encountered by the pathologist.

\section{HISTOLOGICAL STUDIES}

During the past three years clinical trials have been conducted with various progestational agents in the Western Infirmary, Glasgow. In the evaluation of the endometrial response to such compounds it was apparent that the endometrial patterns were not similar to those seen at any stage of the normal menstrual cycle and consequently it was impossible to date the endometrium by the criteria enumerated by Noyes, Hertig, and Rock (1950). It has been shown by Hertig (1946) that the endometrium shows regular and progressive changes in the normal woman following ovulation. Any compound with progestational activity should produce endometrial patterns with some semblance to the normal secretory endometrium but all the derivatives of the 19-norsteroids and 17ahydroxyprogesterone produce bizarre features in the endometrium.

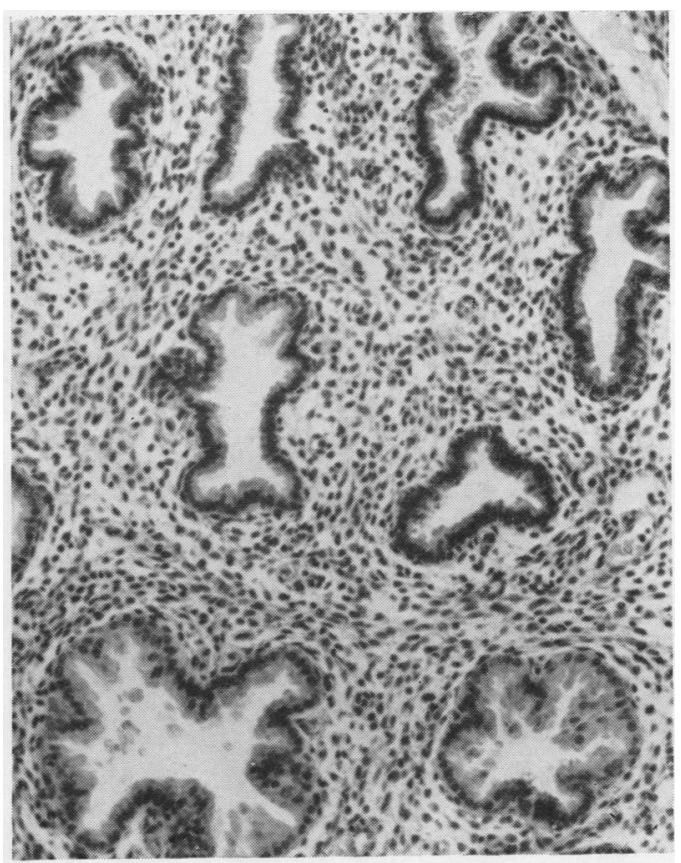

FIG. 4. Endometrium from the lower segment from the same patient as in Fig. 3 showing less obvious hormonal response. Haemalum and eosin $\times 119$.

Both groups of compounds have been administered in a cyclical manner in conjunction with an oestrogen and despite their different chemical structure produce a similar discrepancy between the extent of the glandular and stromal changes invoked in the endometrium. Initially cellular changes in the glands are a prominent feature and subnuclear and supranuclear vacuolations appear in an endometrium which is in the proliferative phase of the cycle. These compounds are administered from the fifth to the twenty-fifth day of a cycle and as a result on the ninth day of the cycle, when simple tubular glands should be present, the vacuolation is comparable to the seventeenth day of a normal cycle (Fig. 5). In endometrium examined later in the cycle marked glandular stromal dissociation is apparent, as the glands fail to progress to the tortuous appearances associated with the secretory phase of the cycle. The glands regress to an inactive state while the stroma becomes oedematous, the stromal cells have a cytoplasmic mantle and adopt a 'decidua-like' appearance. The stromal cells never assume the appearance of the large pale eosinophilic decidual cell found in early pregnancy and as a result no difficulty should exist in the differentiation from the endometrial pattern of early pregnancy (Figs. 6 and 7). The stromal changes are associated 


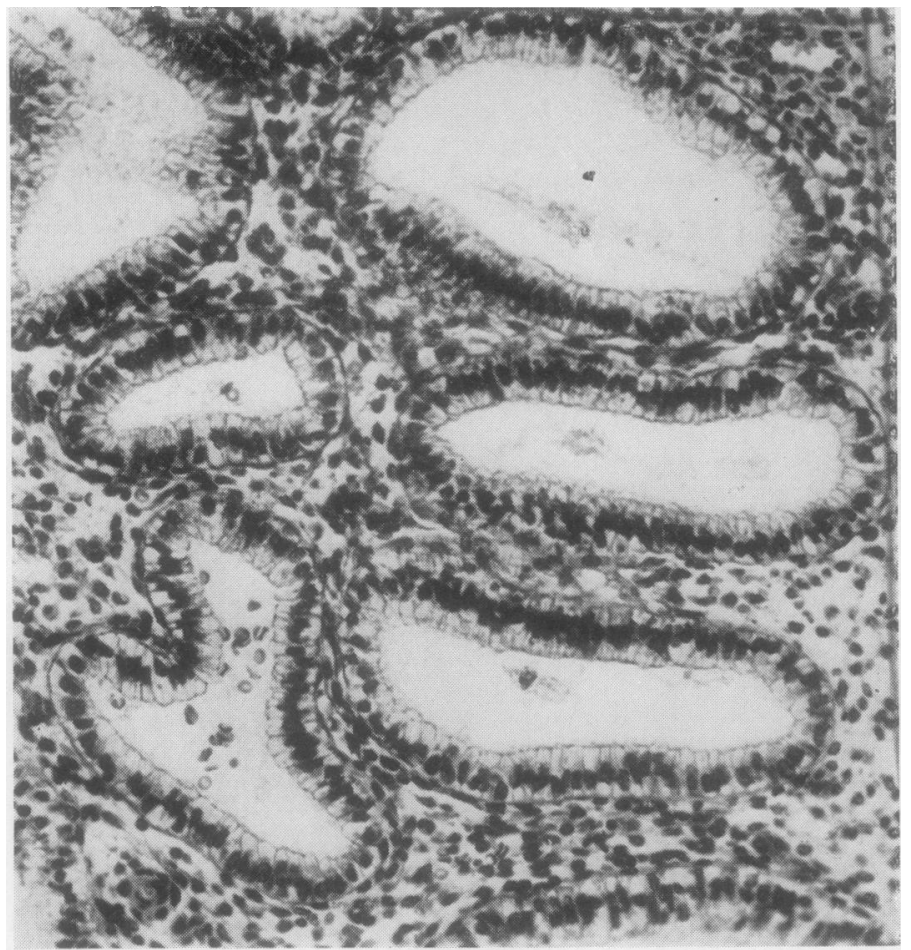

FIG. 5. Endometrium obtained on the ninth day of the menstrual cycle during treatment with norethisterone; the appearances approximate to those of the seventeenth day of a normal cycle. Haemalum and eosin $\times 255$.

FIG. 6. Early pregnancy endometrium showing foamy vacuolated gland cells with focal nuclear variation, the Arias-Stella reaction. Haemalum and eosin $\times 285$.

FIG. 7. Changes induced in endometrial glands and stroma by norethynodrel; the stroma resembles decidua but the gland pattern is not that of pregnancy. Haemalum and eosin $\times 410$.

FIG. 5

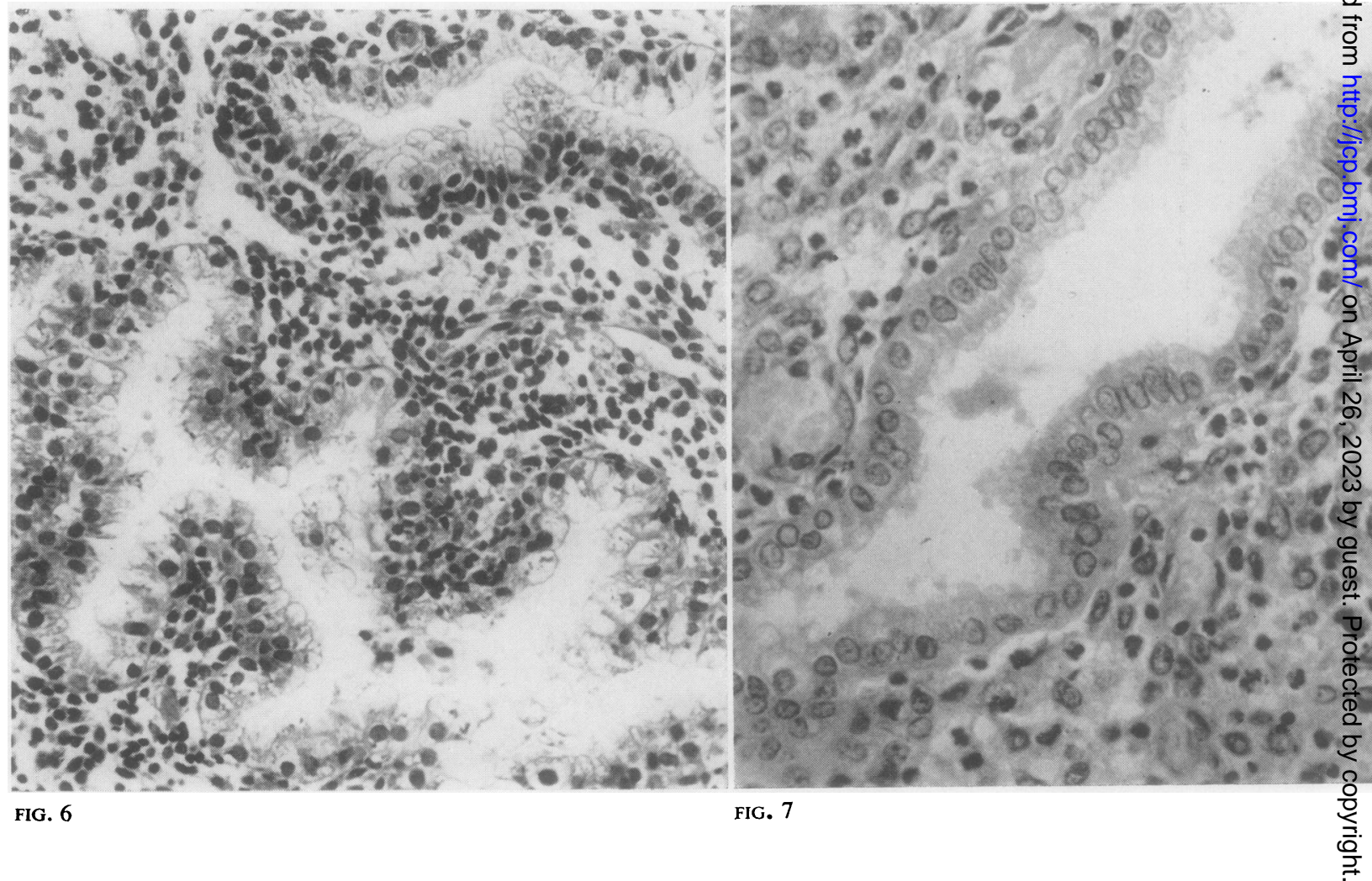




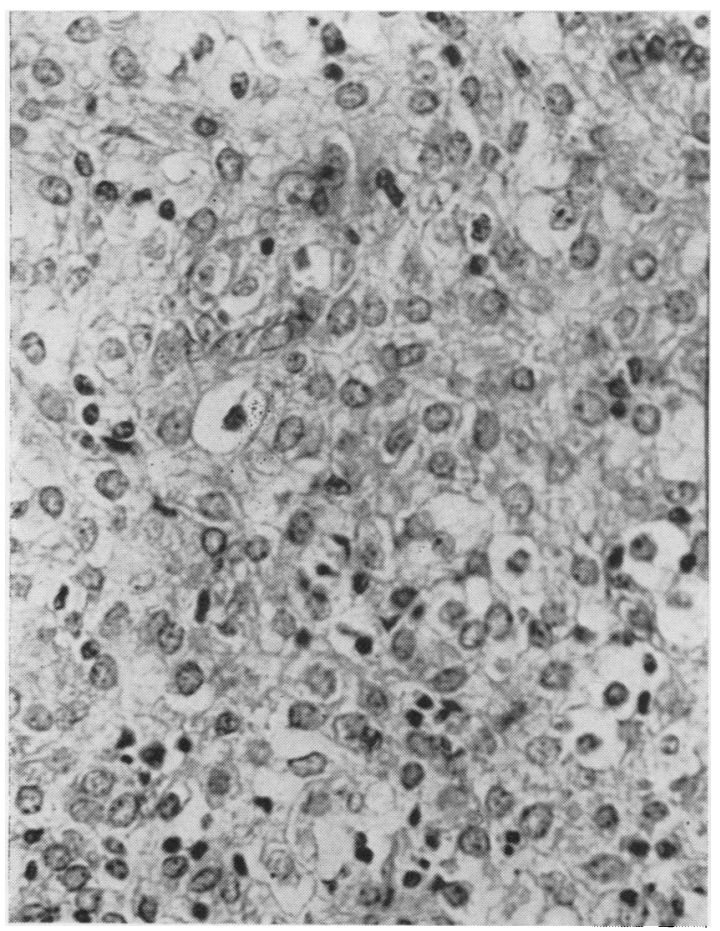

FIG. 8. Decidua-like response elicited in the stroma by Enovid therapy. Haemalum and eosin $\times 309$.

with inactive tubular glands; no focal glandular atypia with enlarged hyperchromatic glandular nuclei have therefore been seen as a result of therapy with synthetic progestational agents. The endometrial response varies with the dose and duration of therapy. The effect of duration of therapy is well exemplified by the administration of these compounds for functional uterine bleeding. Histological examination after therapy for only 48 hours shows glandular changes in the form of vacuolation but if therapy is continued the glands assume an inactive pattern and the stromal cells reveal a decidua-like response (Fig. 8).

Patients frequently enter hospital because of dysfunctional uterine bleeding without volunteering the fact that they have been using oral contraceptive agents. The endometrium in such cases often presents bizarre features, especially when patients have taken these compounds for many months. A case in point is illustrated by Figs. 9 and 10; the patient had used Conovid for six months and had recently developed irregular profuse uterine bleeding. The endometrial glands in some areas exhibited evidence of tubal metaplasia but other glands showed the presence of intraluminal haematoxyphilic globules (Fig. 9). The globules proved to be cytoplasmic in origin by differential staining methods and the fact that they were not Feulgen positive.

It has been stated by Goldzeiher, Rice-Wray, Schulz-Contreras, and Aranda-Rosell (1962) that on discontinuation of therapy there is reversion to a normal endometrial appearance. In the past year several patients who have received cyclical therapy with norethisterone have had abnormal endometrial patterns. One patient aged 22 years, who had cyclical therapy for six months for dysmenorrhoea, had menorrhagia for five months after therapy had been discontinued. The endometrial tissue obtained revealed marked squamous metaplasia (Fig. 11) without evidence of endometrial carcinoma. It is interesting to note that it had previously been considered that transformation of columnar epithelium was indicative of malignant disease (Fluhmann, 1928). In this case the squamous metaplasia had resulted from excessive hormonal stimulation. A further patient with a similar history had a histological pattern of endometrial hyperplasia associated with dense periglandular fibrous stroma (Fig. 12). One further patient had cyclical therapy for nine months, and three months after completion of therapy a curettage was required because of menorrhagia and the endometrial histology revealed a small fibromyoma arising in the endometrium (Fig. 13).

Prolonged progestational therapy in a continuous dosage in the treatment of endometriosis will produce marked morphological changes in the endometrium. Scant small inactive tubular glands, associated with a dense fibrous stroma containing large fibroblast-like cells containing plump nuclei, are observed (Fig. 14). The stromal pattern bears no resemblance to the stroma found in the postmenopausal endometrium but the glands have the appearance of post-menopausal glands.

\section{DISCUSSION}

The only progestational agents which were available until a few years ago were progesterone and ethisterone and they were considered to be of doubtful therapeutic value. The oral administration of the new progestational agents has resulted in widespread clinical application, and it is essential that the pathologist acquires information concerning previous or present therapy when bizarre endometrial patterns are encountered in women during reproductive life.

The endometrial patterns which result from therapy with the 19-nor-steroids and 17ahydroxyprogesterone derivatives are similar and a marked feature is that the histological patterns do not correspond to any stage of the secretory phase of the 


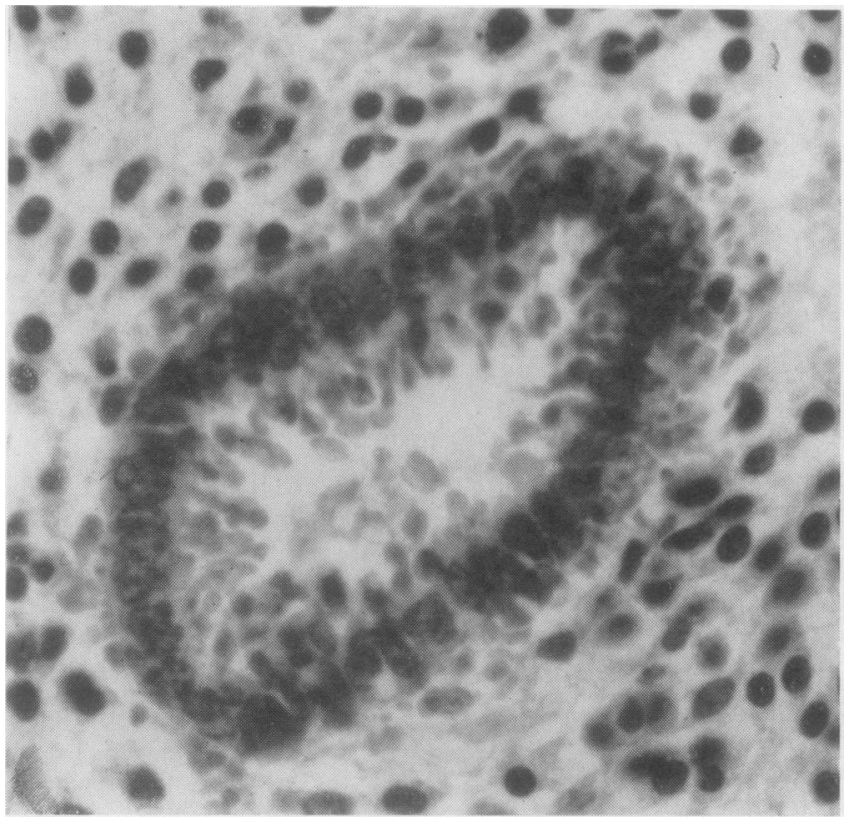

FIG. 9

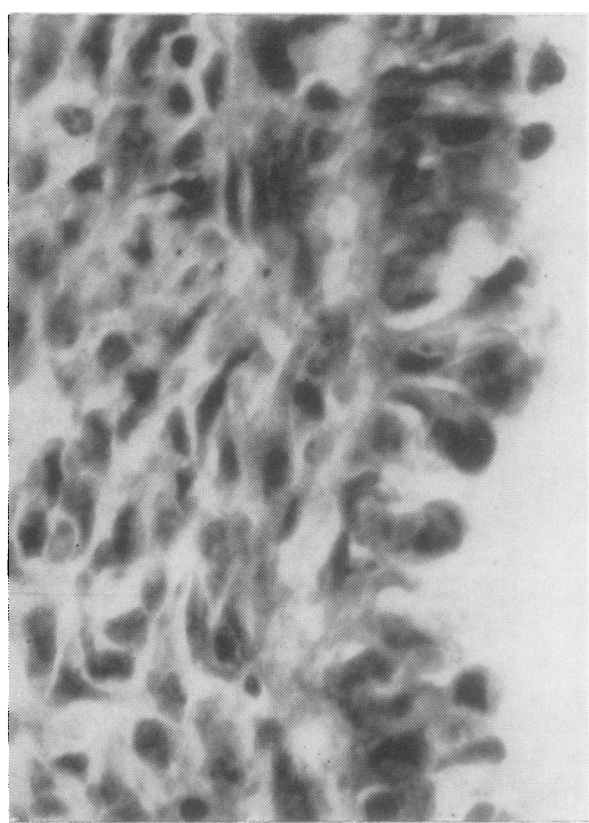

FIG. 10

FIG. 9. Endometrium obtained during Conovid therapy for contraception; note haematoxyphil globules extruding from the luminal border of the gland cells. Haemalum and eosin $\times 695$.

FIG. 10. Endometrial surface epithelium from the same case as in Fig. 9 showing similar changes. Haemalum and eosin $\times 695$.

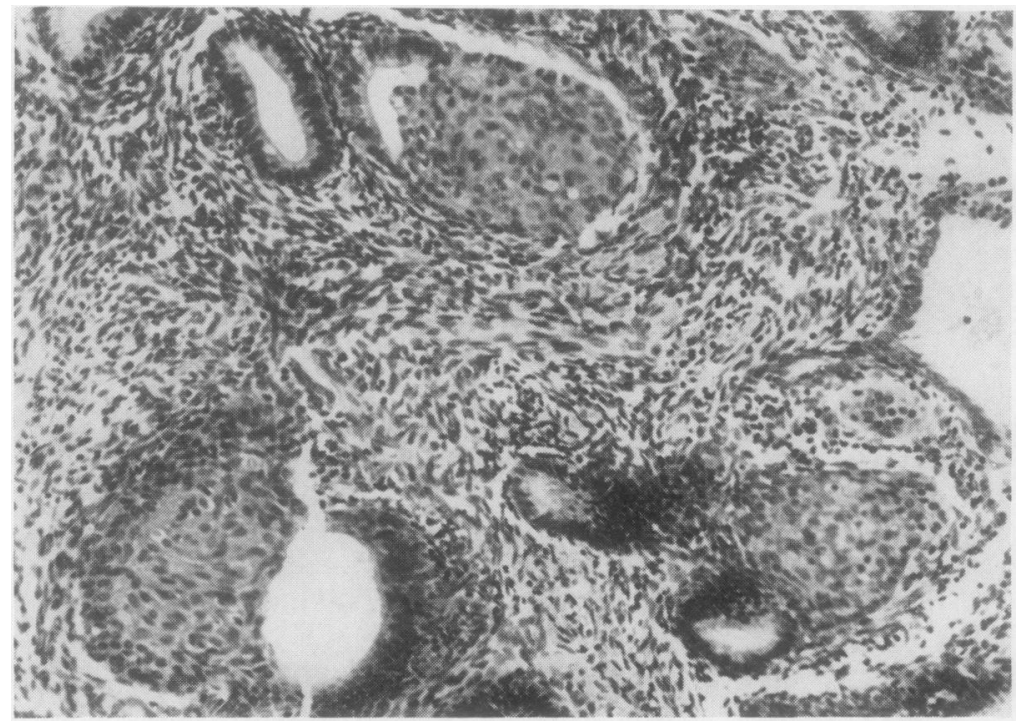

FIG. 11. Squamous metaplasia in endometrial glands four months after discontinuation of norethisterone therapy. Haemalum and eosin $\times 173$. 

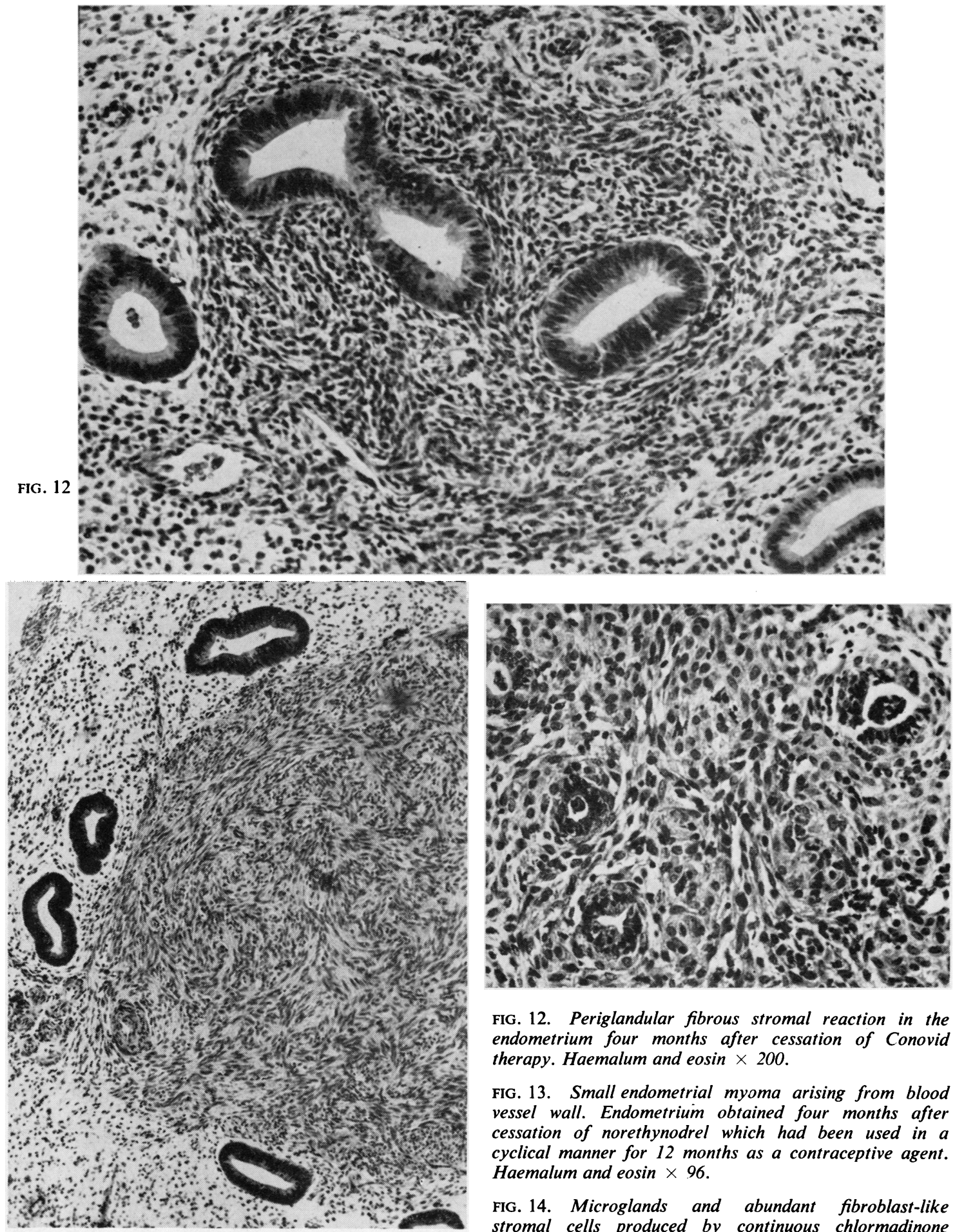

FIG. 12. Periglandular fibrous stromal reaction in the endometrium four months after cessation of Conovid therapy. Haemalum and eosin $\times 200$.

FIG. 13. Small endometrial myoma arising from blood vessel wall. Endometrium obtained four months after cessation of norethynodrel which had been used in a cyclical manner for 12 months as a contraceptive agent. Haemalum and eosin $\times 96$.

FIG. 14. Microglands and abundant fibroblast-like stromal cells produced by continuous chlormadinone therapy for endometriosis. Haemalum and eosin $\times 240$. 
menstrual cycle. Therapy for two or three days results in glandular changes, as evidenced by vacuolation of the glandular cells and minimal stromal oedema. Continued therapy, however, results in glandular regression but the stromal cells assume a 'decidua-like' appearance. Prolonged therapy, if administered in high dosage, results in atrophic glands and a stroma composed of fibroblast type cells.

Dockerty, Smith, and Symmonds (1959) described pseudo-malignant changes in the endometrium produced by the 19-nor-steroids and indicated that $95 \%$ of the cellular component of the endometrium was stroma while the glands were scant and atrophic. In his cases the stromal cells were large and pale and did not resemble normal stromal cells. In such a case, in the absence of a complete history, the pathologist might consider the possible diagnosis of endometrial stromal sarcoma. The use of progestational agents for several months without interruption of therapy is now an accepted form of treatment for pelvic endometriosis; if inadequate oestrogen therapy is administered the oestrogen antagonistic effect of these compounds is revealed on histological examination of the endometrium (Fig. 14).

The 19-nor-steroids have been shown by Paulsen, Leach, Lanman, Goldston, Maddock, and Heller (1962) to have oestrogenic properties, as when administered to males they produce gynaecomastia, and these compounds also relieve climacteric symptoms in women. Confirmatory evidence was that these workers found increased biologically active oestrogens in the urine when the patients were receiving the compounds. Brown and Blair (1960) had previously shown that ethinyl oestradiol was a metabolite of norethisterone. The conversion of norethisterone in the body to ethinyl oestradiol would indicate that therapy for several months with such a compound could result in excessive hormonal stimulation of the endometrium and in abnormal endometrial patterns such as squamous metaplasia of the columnar epithelium (Fig. 11), endometrial hyperplasia, or growth of fibromyomata (Fig. 13).

Therapy with these compounds produces a bizarre endometrial pattern which cannot be equated with the day of the menstrual cycle or the normal physiological post-ovulatory endometrium. Prolonged periods of therapy can alter the endometrial histological pattern a considerable time and it is essential that the pathologist acquires data of regarding hormone therapy when he encounters a bizarre endometrial pattern.

I wish to thank Mr. G. Kerr for the photographic work.

\section{REFERENCES}

Brown, J. B., and Blair, H. A. F. (1960). Proc. roy, soc. Med., 53, 433. Dockerty, M. B., Smith, R. A., and Symmonds, R. E. (1959). Proc. Mayo Clin., 34, 321.

Fluhmann, C. F. (1928). Surg. Gynec. Obstet., 46, 309.

Goldzieher, J. W., Rice-Wray, E., Schulz-Contreras, M., and ArandaRosell, A. (1962). Amer. J. Obstet. Gynec., 84, 1474.

Hertig, A. T. (1946). Proceedings of Conference on Diagnosis in Sterility, edited by E. T. Engle, p. 93. Thomas, Springfield, Illinois.

Noyes, R. W., Hertig, A. T., and Rock, J. (1950). Fertil. and Steril., $1,3$.

Paulsen, C. A., Leach, R. B., Lanman, J., Goldston, N., Maddock, W. O., and Heller, C. G. (1962). J. clin. Endocr., 22, 1033. 